\title{
Behavior of Pregnant Women against Antenatal Care Visits in Tawaeli Public Health Center Area Palu City
}

\author{
Herman $^{1}$, Rasyika Nurul $^{2}$, Amalia Pratiwi ${ }^{3}$, Sendhy Krisnasari ${ }^{4}$, Pitriani $^{\star}, \dagger, 5$ \\ ${ }^{1}$ Health Promotion Department \\ ${ }^{2}$ Health Promotion Department \\ ${ }^{3}$ Health Promotion Department \\ ${ }^{4}$ Health Promotion Department \\ ${ }^{5}$ Environmental Department, Public Health Faculty, Tadulako University Soekarno Hatta Street KM 9, Palu, 94118, Indonesia
}

ODOI: https://doi.org/10.15520/jcmro.v2i05.157

Accepted 05-05-2019; Received 23-04-2019; Publish Online 07-05-2019

Reviewed By: DR. DHARY ALEWY ALMASHHADANY Department: Reviewer/CMRO

\begin{abstract}
Complications of pregnancy and childbirth as the highest cause of maternal death can be prevented through antenatal care regularly. The World Health Organization (WHO) estimates that 800 women die every day due to complications of pregnancy and childbirth. Based on data from the Central Sulawesi Provincial Health Office AKI in 2015 amounting to 208 per 100,000 live births the figure is still relatively high. The data from the Palu City Health Office in 2017 ANC service coverage from the 12 lowest health centers was in the Tawaeli Health Center, namely K1 94.0\% and K2 $85.7 \%$. The purpose of this study was to determine the behavior of pregnant women on antenatal care visits in the working area of Tawaeli Health Center, Tawaeli District, Palu City. This type of research is qualitative with the phenomenology approach. The research informants were 11 people who were determined by Purposive Sampling techniques. The results of this study indicate that knowledge is not good enough because pregnant women get less information about pregnancy and antenatal care examinations. negative attitude in conducting $\mathrm{K} 1$ visits and low K4 visits. Health facilities are sufficient. Family support is good but it has little effect on the regularity of pregnant women in conducting antenatal care visits. Midwives have less role in providing information to pregnant women about antenatal care examinations. It is expected that the Tawaeli Health Center can increase the role of midwives to provide information to pregnant women about pregnancy and antenatal care examinations.
\end{abstract}

Key words: Behavior of Pregnant Women-Antenatal Care

\section{INTRODUCTION:}

The maternal mortality rate (MMR) is one indicator to see the health status of a country. The number of maternal deaths in developing and underdeveloped countries is high as is the case in Sub-Saharan Africa and South Asia ${ }^{[1]}$. Efforts to improve maternal health have been carried out, both at national and international levels, at the international level (WHO) estimates that 800 women die every day due to complications of pregnancy and childbirth. About $99 \%$ of all deaths occur in developing countries. $80 \%$ of maternal deaths are a result of increased complications of pregnancy,

\footnotetext{
* Corresponding author.

$\dagger$ Email: pitriarifink107@gmail.com
}

childbirth and after delivery ${ }^{[2]}$.

Indonesia Maternal mortality rates based on the Indonesian Health Demographic Survey in 2012 amounted to 359 per 100,000 live births. This figure is still far enough to reach the target of reducing the Maternal Mortality Rate (MMR) in 2015 by 102 per 100,000 live births [3]. Based on data from the Central Sulawesi Provincial Health Office the Maternal Mortality Rate in 2011 was 221 per 100,000 live births, in 2012 it was 181 per 100,000, in 2013 it increased 245 per 100,000 , in 2014 there was a decrease of 215 per 100,000 and in 2015 it decreased to 208 per 100,000 [4].

The cause of the highest incidence of maternal death every year is the same, namely due to bleeding. Followed by hypertension and infections and other causes such as cancer, heart disease, tuberculosis, or other diseases that the 


\section{The Analysis of Environmental Risk and the Use of Repellent on Dengue Hemorrhagic Fever in Kamonji Public Health Center

mother suffers. Meanwhile, prolonged abortion and parturition contribute very small numbers as a cause of maternal mortality [5].

Complications of pregnancy and childbirth as the highest cause of maternal death can be prevented by regular antenatal care checks. Antenatal care or antenatal care carried out by trained and professional health personnel can prevent and detect complications in the fetus and pregnant women early so there are no unwanted things in the future [5].

The data from the antenatal care report at the hammer health office in 2017 found antenatal care coverage data from 12 Community Health Centers in the city of Palu, the lowest coverage at the Tawaeli Community Health Center, namely K1 (94.0\%) and K4 (85.7\%). While the highest antenatal care coverage data at Kamonji Community Health Center are K1 (106.3) and K4 (101.8). The data of the Tawaeli Community Health Center Antenatal Care service is still far from the minimum service standard of the Palu City Health Office K1 and K4 at 100\%. Based on the background above, the author feels interested in digging deeper into the behavior of pregnant women on antenatal care visits in the working area of the Tawaeli Community Health Center, Tawaeli District, Palu City.

\section{METHODS:}

This type of research is qualitative with a phenomenological approach. This research was carried out in the working area of the Tawaeli Community Health Center on March 8-May 8, 2018. The informants were determined through a purposive sampling technique, namely key informants were the coordinating midwife of the Tawaeli community health center, ordinary informants were third trimester pregnant women in the work area The Tawaeli community health center and additional informants are husband and family.

\section{RESULT:}

\section{Predisposing factors}

Mother's knowledge

In-depth interviews that the researchers conducted with informants about "what do you know about antenatal care examinations?" Obtained the results that most pregnant women stated that antenatal care examinations were a health check for mothers and infants. When asked "the types of antenatal care checks?" The results showed that most pregnant women do not know all types of antenatal care services can only know four to five types of antenatal care checks.

Mother's attitude

An interview was also conducted to see "how many times have you done an antenatal care examination?". The results obtained were that most pregnant women stated that they had already undergone pregnancy checks more than three times and had their first pregnancy check-up at the age of 20 weeks, known to have passed pregnancy examinations in the first trimester.

\section{Enabling factors}

Health facility

In-depth interviews conducted by researchers to pregnant women about "where do you usually get a pregnancy checkup?" the results were obtained that most pregnant women did checks at the community health center or integrated health post. "How is the distance between the location of the mother's house and the community health center?", The results showed that most pregnant women stated that access to the location to the community health center could be affordable. Based on the results of observations conducted by researchers that the availability of Antenatal Care facilities at the Tawaeli community health center has met the established standards.

\section{Strengthening factor}

Support of health workers

Support from officers is also certainly a factor that influences mothers in carrying out Antenatal Care services. So, the researchers asked about "did midwives ever provide counseling about antenatal care services?" The results showed that most of the informants said that there was no counseling conducted by midwives. "Do midwives explain the benefits of antenatal care examinations?" The results of the study also found that most informants stated that midwives did not explain to pregnant women the benefits of antenatal care examinations.

Family support

Support from people closest to the mother is one of the reinforcing factors in this study. The researcher asked about "what kind of support is always given by the family to the mother in carrying out Antenatal Care services?" The results were obtained that the family supported by always reminding the mother to do an Antenatal Care examination and accompanying the mother during pregnancy checkups.

\section{DISCUSSION:}

\section{Mother's knowledge}

In this study, most informants have knowledge in the cognitive domain at the first level, namely "know" can be interpreted as informants only able to recall something specific based on the material being studied or stimuli that have been received. therefore "know" is the lowest level of knowledge in the six levels of knowledge. The level of knowledge of the informants has not yet reached the application level so that they have not been able to use the capabilities or material received for the actual conditions.

This study is in line with the research that says that pregnant women who have good knowledge about the focus of antenatal care have good visits in antenatal care and pregnant women who have poor antenatal care knowledge who have low visits to antenatal care services. ${ }^{[6]}$.

\section{Mother's attitude}

Most pregnant women have a negative attitude towards Antenatal Care services. The attitude of pregnant women 
towards Antenatal Care services at the responding level means that the informants want to do and carry out the tasks given (Antental Care services) regardless of whether the work is right or wrong, this can be seen from the Antenatal Care services that have been done by pregnant women there are some pregnant women who carry out Antenatal Care services that are not in accordance with the standards set by the government, which are at least four times during pregnancy, and most pregnant women are late in carrying out antenatal care, which causes incomplete Antenatal Care examinations in the first trimester.

This research is in line with research that says that timely conduct of antenatal care examinations is generally known as an effective method to prevent loss of pregnancy outcomes. A recent study in Pakistan reported that women whose first Antenatal Care visit occurred within the first 12 weeks of pregnancy received a full range of WHOrecommended care content. However, women whose first Antenatal Care visit occurs late during pregnancy is less likely to receive various services ${ }^{[7]}$.

\section{Health facility}

Based on the results of the study, it was shown that pregnant women in the Tawaeli Community Health Center work area had made good use of the available health facilities, namely the Community Health Center, Village Health Post and Integrated Service Post. As well as the distance to the location can also be affordable. The results of the observations by the researchers showed that the availability of tools for antenatal care service facilities was available such as weight checks, blood pressure checks, upper arm circumference measuring devices, uterine examination tools, tools for determining fetal presentation and fetal heart rate and laboratory examination. The completeness of Antenatal Care facilities (10T) can affect the quality of Antenatal Care services for pregnant women because pregnant women can get complete and standardized Antenatal Care services.

The Tawaeli Community Health Center also has health facilities for pregnant women that have not been implemented properly by the Community Health Center. the ineffectiveness of class facilities for pregnant women can affect Antenatal Care visits, because in class facilities pregnant women have a lot of information about pregnancy health and Antenatal Care services. The lack of information on Antenatal Care services has an effect on the low knowledge of pregnant women and thus affects the success of Antenatal Care visits.

This research is in line with research that says that there is a relationship between counseling the use of antenatal care services with increased knowledge. The need for more intensive counseling and counseling from health workers, especially midwives in health centers, on the importance of prenatal care so that they are more regularly checked for pregnancy so that the health condition of the mother and fetus is maintained. For this reason, it is necessary to make counseling about prenatal care as a routine activity in the class of pregnant women and home visits ${ }^{[8]}$.

Health Officer Support
Based on the results of research conducted by researchers, it was found that the role of health workers in the Tawaeli Community Health Center was less instrumental in providing information about Antenatal Care services, the support of health workers in this case providing information or counseling to pregnant women is still not optimal. This is from the statement of all informants who stated that they did not get information about Antenatal Care services.

This research is in line with research that states that the attitude of officers is included in the reinforcing factor that causes pregnant women to take advantage of antenatal services in health services. the better a program is supported by the support of good officers it will increase the effect of synergy in order to achieve the target of reducing maternal and perinatal mortality through various program activities that are in the integrated antenatal care service model in accordance with the characteristics of needs and potential available in the area or facilities health ${ }^{[9]}$.

\section{Family Support}

Based on the results of interviews with informants regarding family support to pregnant women on Antenatal Care visits, it was found that all informants received support from the family in this case parents and husbands to pregnant women in performing antenatal care services. The support obtained by pregnant women in the form of encouragement to routinely carry out antenatal care and there is no prohibition to carry out prenatal checks. Other support is also provided by the family by always accompanying pregnant women in conducting pregnancy checks at health facilities. But also there are still some pregnant women who are not accompanied by their husbands to check for pregnancy, this is because during the examination the husband works. because of the lack of motivation from the family in the form of mentoring support to carry out Antenatal care services, and ensuring compliance with Antenatal care services affects the success of Antenatal care visits. The lack of family in assisting pregnant women is because the husband does not have enough knowledge about prenatal care which means lack of information support, this is evident from the informant's statement stating that he did not know the benefits and impacts of not having a pregnancy check

This research is in line with research that states that the lack of husband's support in antenatal care is caused by the husband being busy working so there is no time to deliver the mother and her husband's knowledge is lacking about the benefits of antenatal care. Lack of husband's support can cause mothers to be less regular in doing antenatal care ${ }^{[10]}$.

\section{CONCLUSION :}

Mother's knowledge and mother's attitudes regarding Antenatal Care visits are still relatively poor. Health facilities at the community health center are already good. Family support is still not maximal while the role of health workers (midwives) is low because of the lack of information 


\section{The Analysis of Environmental Risk and the Use of Repellent on Dengue Hemorrhagic Fever in Kamonji Public Health Center

provided by midwives to pregnant women about Antenatal care services.

Acknowledgement: Thanks to the head of the Tawaeli Public Health Center and all health workers who contributed to this study, which had pleasure participated and supported this research.

Conflict of Interest : The authors declare no potential conflict of interest in this research

\section{REFERENCES}

[1] O WH. Media Center (Maternal Mortality); 2013. Http://w ww.who.int/mediacentre/factsheets/fs348/en/ (Citation on October 27.

[2] Maternal Mortality. World Health Organization (WHO). 2014; Citation on October 27. Available from: Http://www. who.int/mediacentre/factsheets/fs348/en/.

[3] Pregnant at the Ngemplak Simongan. Public Health Journal. 2015;3(3):88-98.

[4] Sulawesi Province in 2015. Central Sulawesi Provincial Health Office Health Profile of Central;.

[5] Factors Affecting Antenatal Care (ANC) Visits for Pregnant Women. Majority. 2017;7(1):72-76.

[6] Idang NO, Adora UL, Catherine C, N. Knowledge And Attitude Of Pregnant Women Towards Focused Christmas. Midwife and Health Related Cases. 2015;1(1):14-33.

[7] at all 7 Yaya S. Timing and adequate attendance of antenatal care visits among women in Ethiopia. Plos One; 2017.

[8] Lamama V, S S, D, M K, D. Effect of Counseling About Pregnancy Examination on Increased Knowledge of Pregnant Women. Midwife Scientific Journal. 2015;3(1):66-72.

[9] Damopolii TA, Kundre R, Bataha Y. Relationship between Antenatal Care Service Standards and Policy for Antenatal Care Services with Integrated Antenatal Care Knowledge in the. Work Area of Gogagoman Health Center in Kotamobagu City Nursing Journal. 2015;3(2):1-7.

[10] Relationship between Knowledge and Family Support with Antenatal Care Visits for Pregnant Women in the Olak Kemang. Public Health Center Area Jambi City Public Health Journal. 2017;1(1):8-17. 